\title{
Map-based cloning and functional analysis of $Y G L 8$, which controls leaf colour in rice (Oryza sativa)
}

Xiaoyan Zhu ${ }^{1 \dagger}$, Shuang Guo ${ }^{1,2 \dagger}$, Zhongwei Wang ${ }^{1 \dagger}$, Qing Du ${ }^{1,3}$, Yadi Xing ${ }^{1}$, Tianquan Zhang ${ }^{1}$, Wenqiang Shen ${ }^{1}$, Xianchun Sang ${ }^{1}$, Yinghua Ling ${ }^{1}$ and Guanghua $\mathrm{He}^{1 *}$

\begin{abstract}
Background: As the indispensable part of plant, leaf blade mainly functions as the production workshops where organic substance is produced by photosynthesis. Leaf colour mutation is a genetic phenomenon that has a high frequency and is easily identified. The mutations always exhibit negative impact on the development of plants in any of the different stages of growth. Up to now, numerous genes involved in leaf colour mutations have been cloned.

Results: In this study, a yellow-green leaf mutant, yellow-green leaf 8 (yg/8), with stable genetic phenotype, has been screened out in the progeny of an excellent indica restorer line Jinhui 10 with seeds treated by EMS. The levels of $\mathrm{Chl} a, \mathrm{Chl} b$ and total chlorophyll were significantly lower in yg/8 than those in the WT throughout the whole growth period, while no clear change was noted in the $\mathrm{Chl} a / b$ ratio. Transmission electron microscopy demonstrated that the lamellae were clearly intumescent and intricately stacked in yg/8. Furthermore, compared with those of the WT, the stomatal conductance, intercellular $\mathrm{CO}_{2}$ concentration, photosynthetic rate and transpiration rate of ylg8 were all significantly lower. Map-based cloning results showed that Loc_Os01g73450, encoding a chloroplast-targeted UMP kinase, corresponded to Ygl8 and played an important role in regulating leaf colour in rice (Oryza sativa). Complementation of yg/8 with the WT DNA sequence of Loc_Os01g73450 led to restoration of the normal phenotype, and transgenic RNA interference plants showed a yellow-green colour. Analysis of the spatial and temporal expression of Ygl8 indicated that it was highly expressed in leaf blades and weakly expressed in other tissues. QRT-PCR also showed that the expression levels of the major Photosystem I core subunits plastome-encoded PsaA, PsaB and PsbC were significantly reduced in yg/8. The expression levels of nuclear-encoded gene involved in Chl biosynthesis HEMC, HEME, and PORA were also decreased when compared with the wild-type.
\end{abstract}

Conclusions: Independent of Chl biosynthesis and photosystem, YGL8 may affect the structure and function of chloroplasts grana lamellae by regulating plastid genome encoded thylakoid membrane constitutive gene expression and indirectly influences Chl biosynthesis.

Keywords: Rice (Oryza sativa), Yellow-green leaf 8 (yg/8), Map-based cloning, Functional analysis

\footnotetext{
*Correspondence: hegh@swu.edu.cn

${ }^{\dagger}$ Equal contributors

${ }^{1}$ Key Laboratory of Application and Safety Control of Genetically Modified

Crops, Rice Research Institute of Southwest University, Chongqing 400716,

China

Full list of author information is available at the end of the article
} 


\section{Background}

Leaf colour mutation occurs commonly in the natural world. There are abundant phenotypes and the mutations can exhibit their effects in any of the different stages of growth. With regard to the classification of leaf colour mutants, numerous different categories have been established. Gustafsson classified leaf colour mutants into albino, chlorina, stripe, virescent and zebra [1]. Later, Awan et al. subdivided them into eight classes: albino, xantha, viridis, alboviridis, viridoalbino, xanthaviridis, viridoxantha and striata [2]. With regard to the physiological mechanisms involved, leaf colour mutations were divided by Falbel and Staehelin into total chlorophyll (Chl) increase type, total Chl deficiency type, Chl $a$ deficiency type and $\mathrm{Chl} b$ deficiency type [3].

To date, the locations of more than 100 leaf colour mutations have been determined in rice and have been shown to be distributed across all 12 chromosomes. Over 40 genes involved in leaf colour mutations have been cloned, more than 10 of which were found to be chlorina genes. Examples of these include OsHAP3A, $O s H A P 3 B$ and OsHAP3C, which are three yellowing genes that were shown to control chloroplast biosynthesis [4]. OsCAO1 and OsCAO2 were both found to encode Chl a oxygenase, which is the key enzyme for the catalytic synthesis of Chl b [5]. Ygll was shown to encode Chl synthase, which catalyses conversion of chlorophyllide $a$ into $\mathrm{Chl} a$, the final step in the biosynthesis of $\mathrm{Chl} a$ [6]. $V y l$ encodes a protein homologous to the Arabidopsis caseinolytic protease P6 subunit and is targeted to the chloroplast [7]. $V 2$ was found to encode a new type of guanylate kinase (GK, ATP: GMP phosphotransferase), which is the key enzyme in guanine metabolic pathways and participates in regulating the transmission of chloroplast development signals to the nucleus [8]. $Y g l 2$ encodes a heme oxygenase, which is the initial and rate-limiting enzyme that catalyses heme degradation [9]. V3 encodes the large subunit of ribonucleotide reductase, which controls the rate of synthesis of DNA nucleotides and affects DNA synthesis and repair [10]. There are also CHL1 and CHL9, which respectively encode the ChlD and ChlI subunits of Mg-chelatase, a key enzyme for Chl synthesis and chloroplast development [11]. Newly identified Ygl6 gene encoding a putative 3- $\beta$ hydroxysteroid dehydrogenase/isomerase family protein might be involved in the synthesis of brassinosteroids, and it shows sequence similarity to human and mouse proteins involved in the synthesis of androgens, progestins, and estrogens [12]. Recently, another gene, $Y g l 7$, an allele of the OsChlD gene, was identified. The $y g l 7 \mathrm{mu}-$ tant uses light energy efficiently when compared with the wild-type, which demonstrated that the YGL7 protein might promote photosynthesis [13]. Besides V2, V3, and $Y g l 6$, other cloned leaf colour mutation genes were almost directly involved in Chl metabolism or chloroplast development.

Pyrimidine nucleotides represent one of the most fundamental cellular components with essential functions in multiple cellular processes. They are not only building blocks for nucleic acid synthesis in dividing and elongating tissues, but also participate in lipid and carbon metabolism such as UDP-glucose as precursor in sucrose or cell wall biosynthesis. Pyrimidine nucleotides are synthesized both from amino acids and other small molecules via de novo pathways, and from preformed nucleobases and nucleosides by salvage pathways. UMP kinase which catalyses the phosphorylation of UMP to UDP, with ATP as the preferred donor [24] plays a crucial role in pyrimidine nucleotides de novo synthesis and functions in supplying precursors for nucleic acid synthesis by catalyzing the conversion of UMP into their diphosphate form. The functions of UMP kinase in cell proliferation and physiology have been widely studied. It has been reported that in both bacteria and yeast, the mutation of UMP kinase represses cell proliferation and physiology [14, 15]. In addition, Giblett et al. [16] has reported that the phenotype of down-regulated UMP kinase was similar to the immune defect resulting from adenosine deaminase deficiency. However, in plants, only a few studies on UMP kinase have been carried out [17, 18]. Zhou et al. has demonstrated the Arabidopsis thaliana UMP/CMP kinase activity by complementation of a Saccharomyces cerevisiae ura6 mutant [17]. The mutation of an Arabidopsis prokaryotic UMP kinase has defects in $p s a A / B$ transcript accumulation and leads to growth and development retardation of the mutant plants [18].

To date, numerous proteins involved in Chl biosynthesis and assembly and regulation of the photosystems have been identified, greatly broadening our understanding of their function in crop yield. Our knowledge about the function of UMP kinase in rice and its function in regulating the photosystems and Chl biosynthesis is still limited. Here, we report the identification of ygl8 (yellow-green leaf 8), a new leaf colour mutant in O. sativa. The ygl8 mutant exhibits abnormal grana lamellae and a yellow-green phenotype. YGL8 protein is a nuclear encoded chloroplast targeted protein which shares high sequence similarity with cyanobacterial UMP kinase. Possible roles of YGL8 in regulating photosystem and Chl biosynthesis are discussed.

\section{Results}

The $\mathrm{Yg} / 8$ gene mutation led to less $\mathrm{Chl}$ accumulation and destroyed the structure of grana lamellae

A yellow-green leaf mutant, ygl8, derived from a process of ethyl methane sulfonate (EMS) mutagenesis 
and exhibiting a yellow-green leaf phenotype throughout the entire growth period, was identified (Fig. 1a-c). Its level of Chl was significantly decreased throughout the whole growth period, especially at the tillering stage when it was only $37.30 \%$ of the normal (wild-type; WT) level. This mutant also had Chl reductions of $59.24 \%$ at the seedling stage and $57.47 \%$ at the heading stage. More specifically, the levels of both Chl $a$ and Chl $b$ were significantly lower in $y g l 8$ than those in the WT throughout the whole growth period. However, the ratio of $\mathrm{Chl} a / b$ changed little between the ygl8 mutant and the wildtype, with a slight increase in $y g l 8$ at the seedling and tillering stages. The decrease in Chl level corresponded perfectly to the level of yellowness of the leaves (Table 1).

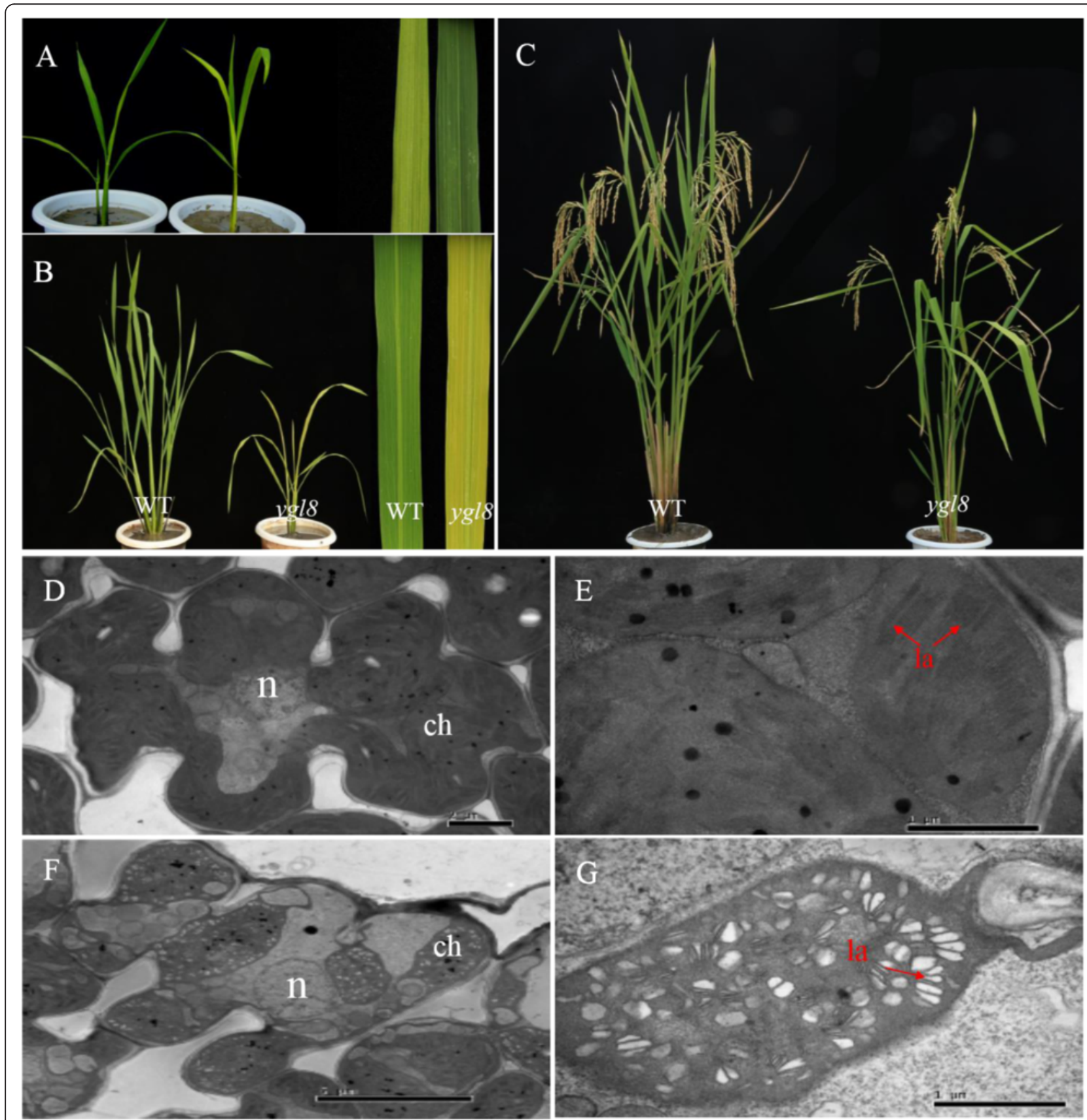

Fig. 1 The phenotype, cytology and agronomic traits of the wild-type and yg/8 mutant. $\mathbf{a}$ : The phenotype at the seedling stage; $\mathbf{b}$ : the phenotype at the tillering stage; $\mathbf{c}$ : the phenotype at the mature stage; $\mathbf{d}-\mathbf{e}$ : cytological analysis of the $\mathbf{W T} ; \mathbf{f}-\mathbf{g}$ : cytological analysis of ygl8; ch: chloroplast; la: grana lamella; n: nucleus 
Table 1 Levels of various photosynthetic pigments in leaves of the mutant and the wild-type at the seedling, tillering and heading stages

\begin{tabular}{|c|c|c|c|c|c|}
\hline & & $\mathrm{Chl} a\left(\mathrm{mg} \mathrm{g}^{-1} \mathrm{FW}\right)$ & $\mathrm{Chl} b\left(\mathrm{mg} \mathrm{g}^{-1} \mathrm{FW}\right)$ & Total Chl $\left(\mathrm{mg} \mathrm{g}^{-1} \mathrm{FW}\right)$ & $\mathrm{Chl} a / b$ ratic \\
\hline \multirow[t]{2}{*}{ Seedling stage } & WT & $3.03 \pm 0.13$ & $0.60 \pm 0.03$ & $3.63 \pm 0.15$ & $5.05 \pm 0.23$ \\
\hline & $y g / 8$ & $1.25 \pm 0.14^{* *}$ & $0.23 \pm 0.03^{* *}$ & $1.48 \pm 0.17^{* *}$ & $5.44 \pm 0.24$ \\
\hline \multirow[t]{2}{*}{ Tilling stage } & WT & $3.40 \pm 0.10$ & $0.69 \pm 0.08$ & $4.09 \pm 0.13$ & $4.93 \pm 0.18$ \\
\hline & $y g / 8$ & $1.29 \pm 0.03^{* *}$ & $0.23 \pm 0.01^{* *}$ & $1.53 \pm 0.08^{* *}$ & $5.60 \pm 0.29$ \\
\hline \multirow[t]{2}{*}{ Heading stage } & WT & $3.55 \pm 0.26$ & $0.83 \pm 0.06$ & $4.38 \pm 0.32$ & $4.29 \pm 0.06$ \\
\hline & $y g / 8$ & $1.48 \pm 0.14^{* *}$ & $0.38 \pm 0.12^{* *}$ & $1.86 \pm 0.23^{* *}$ & $4.10 \pm 0.79$ \\
\hline
\end{tabular}

Fw indicates fresh weight; ${ }^{* *}$ means significantly different compared with the corresponding WT at $p<0.01$ by the Student's $t$ test

To investigate whether the $y g l 8$ mutation affects chloroplast development, we compared the ultrastructure of chloroplasts in $y g l 8$ and the WT at the seedling stage using TEM. There were normal cells and chloroplasts in the WT (Fig. 1d-e). We also found that the cells in ygl8 maintained their structural integrity (Fig. 1f); however, the grana lamellae of chloroplasts were clearly intumescent and intricately stacked in $y g l 8$ (Fig. 1g).

Most of the main agronomic traits were significantly worse in $y g l 8$ than those in the WT, especially plant height, effective panicle number per plant, grain number per panicle, filled grain number per panicle, and seed setting rate; however, 1000 -grain weight showed no clear difference (Fig. 2a-f; Additional file 1).

\section{Photosynthetic capacity was affected by the mutation of YGL8}

Photosynthetic parameters were analysed at the heading stage using an LI-6400 portable photosynthesis meter (LiCor, Lincoln, NE, USA). In $y g l 8$, the stomatal conductance was just $0.058 \mathrm{~mol} \mathrm{H}_{2} \mathrm{O} \mathrm{m}^{-2} \mathrm{~s}^{-1}$, which was only $12.52 \%$ of the value in the WT (Fig. 3a; Additional file 2), and the intercellular $\mathrm{CO}_{2}$ concentration was $218.22 \mu \mathrm{mol} \mathrm{CO} \mathrm{Cm}^{-2} \mathrm{~s}^{-1}$ in ygl8 but $281.75 \mu \mathrm{mol}$ $\mathrm{CO}_{2} \mathrm{~m}^{-2} \mathrm{~s}^{-1}$ in the WT (Fig. 3b; Additional file 2). The photosynthetic rate was significantly decreased in ygl8 compared with that in the WT (Fig. 3c; Additional file 2). Furthermore, the transpiration rate was $2.32 \mathrm{~mol} \mathrm{H}_{2} \mathrm{O} \mathrm{m} \mathrm{m}^{-2} \mathrm{~s}^{-1}$, significantly lower than that of the WT (Fig. 3d; Additional file 2). All of

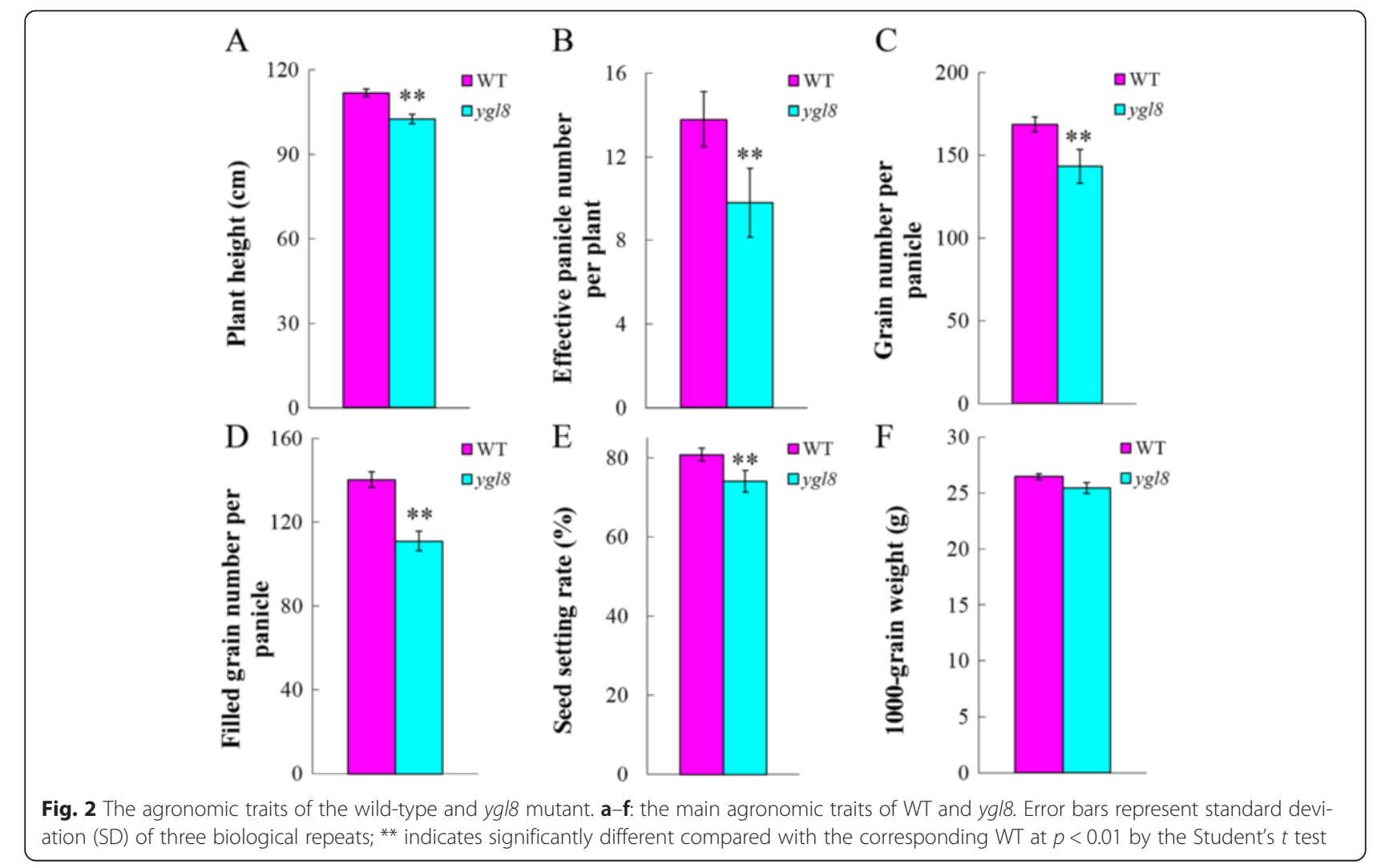



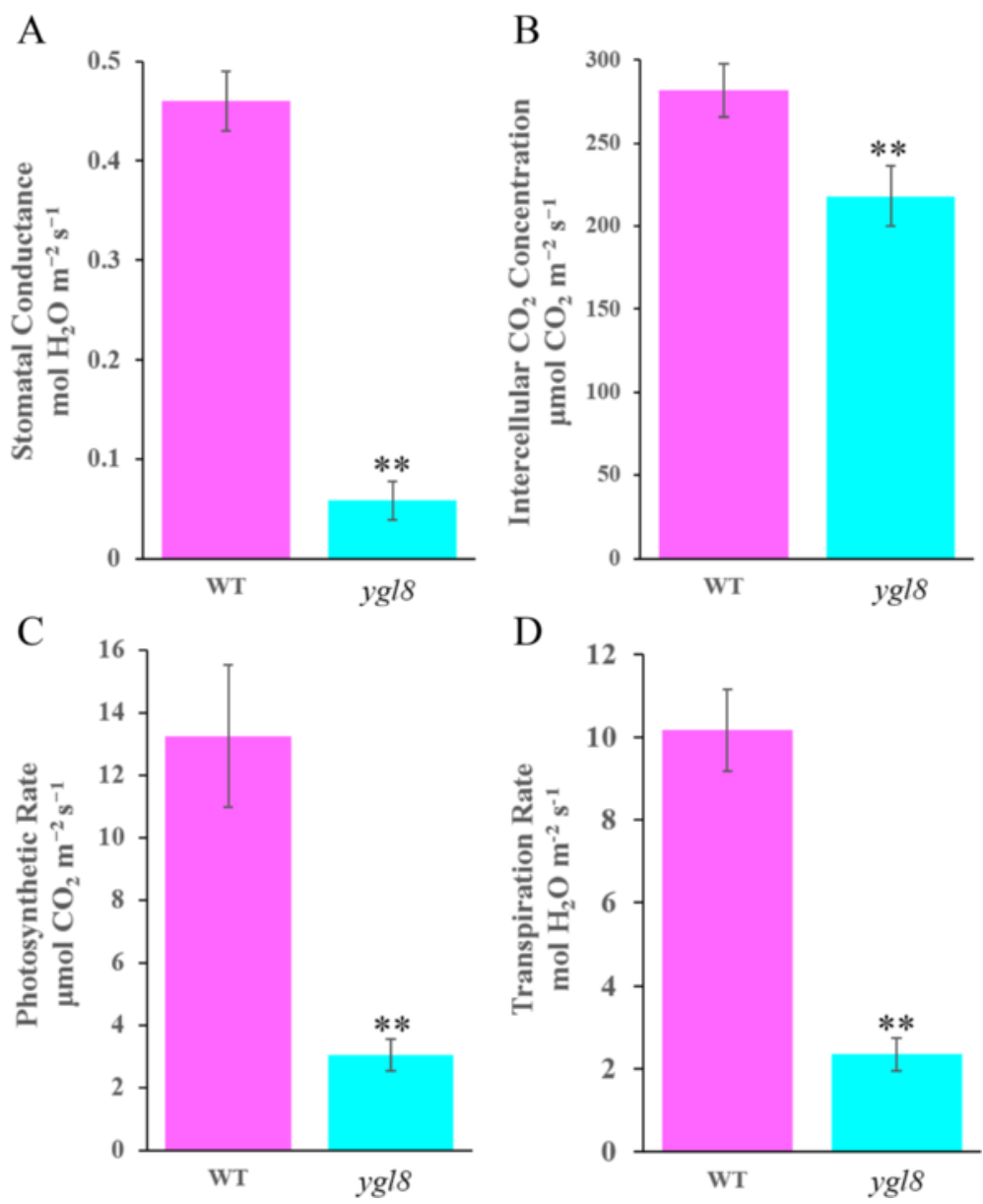

Fig. 3 Comparison of stomatal conductance, intercellular $\mathrm{CO}_{2}$ concentration, photosynthetic rate and transpiration rate between WT and yg/8 at the heading stage. Error bars represent standard deviation (SD) of three biological repeats; ${ }^{* *}$ indicates significantly different compared with the corresponding WT at $p<0.01$ by the Student's $t$ test

these findings indicated that the photosynthetic capacity was deficient in $y g l 8$.

\section{The Ygl8 gene encodes a UMP kinase on chromosome 1}

Genetic analysis showed that the yellow leaf phenotype in $y g l 8$ is controlled by a single recessive nuclear locus with a segregation ratio of $2.987\left(\chi^{2}=0.028<\chi_{0.05}^{2}=\right.$ 3.84). To map the Ygl8 locus, 400 pairs of SSR markers evenly distributed in the rice genome were selected to screen for polymorphism among the parents and the gene pools. RM6141 and RM6321 revealed polymorphism among the parents and the gene pools, respectively. By using $452 \mathrm{~F}_{2}$ recessive plants, the $Y G L 8$ gene was first mapped to the long arm of chromosome 1, between RM6141 and RM6321. To narrow down its location, more than $9000 \mathrm{~F}_{2}$ plants, of which 2360 were recessive, were used for fine mapping. More than 40 In-Del markers and SSR markers were designed, five of which were polymorphic. Finally, we mapped the Ygl8 gene to a 54-kb genomic region between In-Del marker
ID-3 and SSR marker RM12339, and Ygl8 co-segregated with In-Del marker ID-13 (Fig. 4). Within the target region, 11 ORFs were identified using the Gramene website (http://www.gramene.org/). Among the 11 ORFs sequenced, only Loc_Os01g73450 carried a mutation, a single-nucleotide transition $(\mathrm{C} \rightarrow \mathrm{T})$, on the fifth exon at the position 671 bp from the ATG start codon, which resulted in an amino acid change from Ala-224 to Val (Fig. 4) when compared with the wild-type. A search of the rice genome database reveals that Loc_Os01g73450 consists of seven exons and six introns, with a total length of $4177 \mathrm{bp}$. The $1056 \mathrm{bp}$ CDS encodes a UMP kinase with 351 amino acids (Fig. 5). Therefore, we tentatively assigned Loc_OsO1g73450 as the Ygl8 gene.

For the further validation of $Y g l 8$, genetic complementation was carried out by introducing a 6478 bp genomic fragment of WT into ygl8 plants. As expected, the yellow-green leaf phenotype was not observed in any $y g l 8-\mathrm{C}$ transgenic line (Fig. 6a). Furthermore, the level of Chl was restored to the level in the WT (Fig. 6b). Confirming that disruption of 


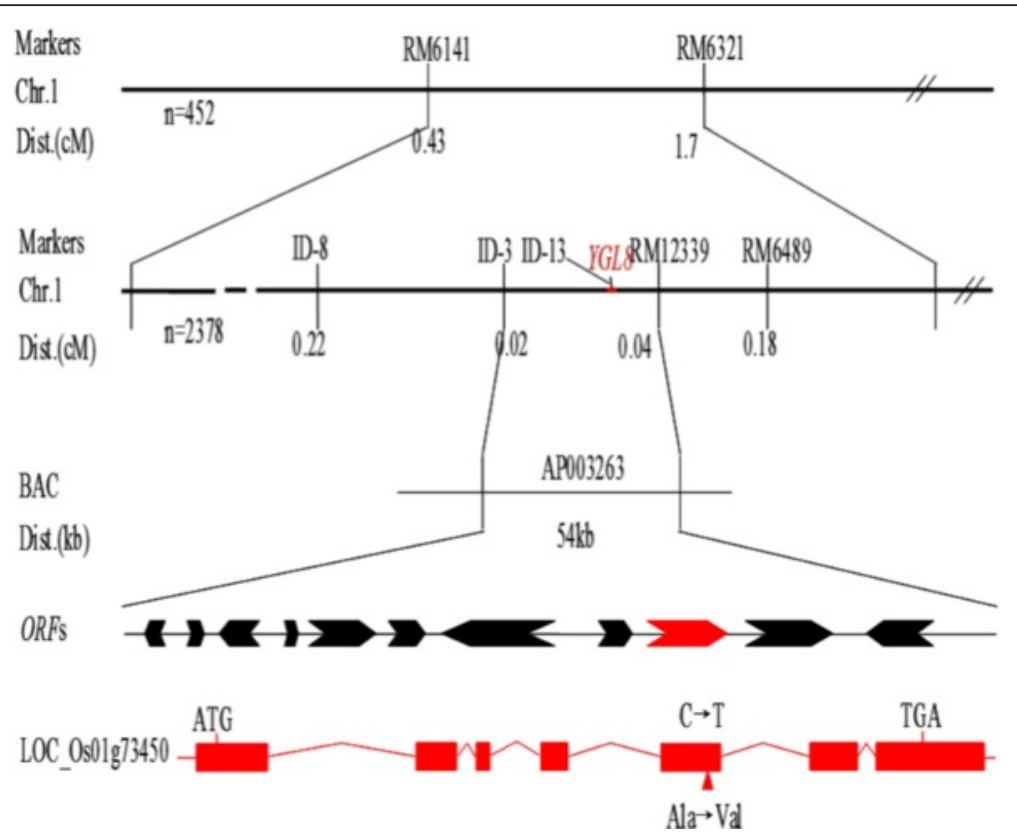

Fig. 4 Map-based cloning and characterisation of YGL8. YGL8 was located on chromosome 1 between In-Del marker ID-3 and SSR marker RM12339 and co-segregated with In-Del marker ID-13

the YGL8 gene was responsible for the ygl8 mutant phenotype, RNAi transgenic plants showed a yellow-green leaf phenotype in which the total Chl level was clearly decreased (Fig. 6c and e). qRT-PCR analysis revealed that the expression of YGL8 was markedly reduced in these transgenic lines compared with that in ZhongHua11 plants (Fig. 6d).
Together, these results confirmed that Loc_Os01g73450 indeed corresponded to the Ygl8 gene.

YGL8 protein belongs to a highly conserved protein family The predicted YGL8 polypeptide consisted of 351 amino acids with a chloroplast transit sequence of 58 amino

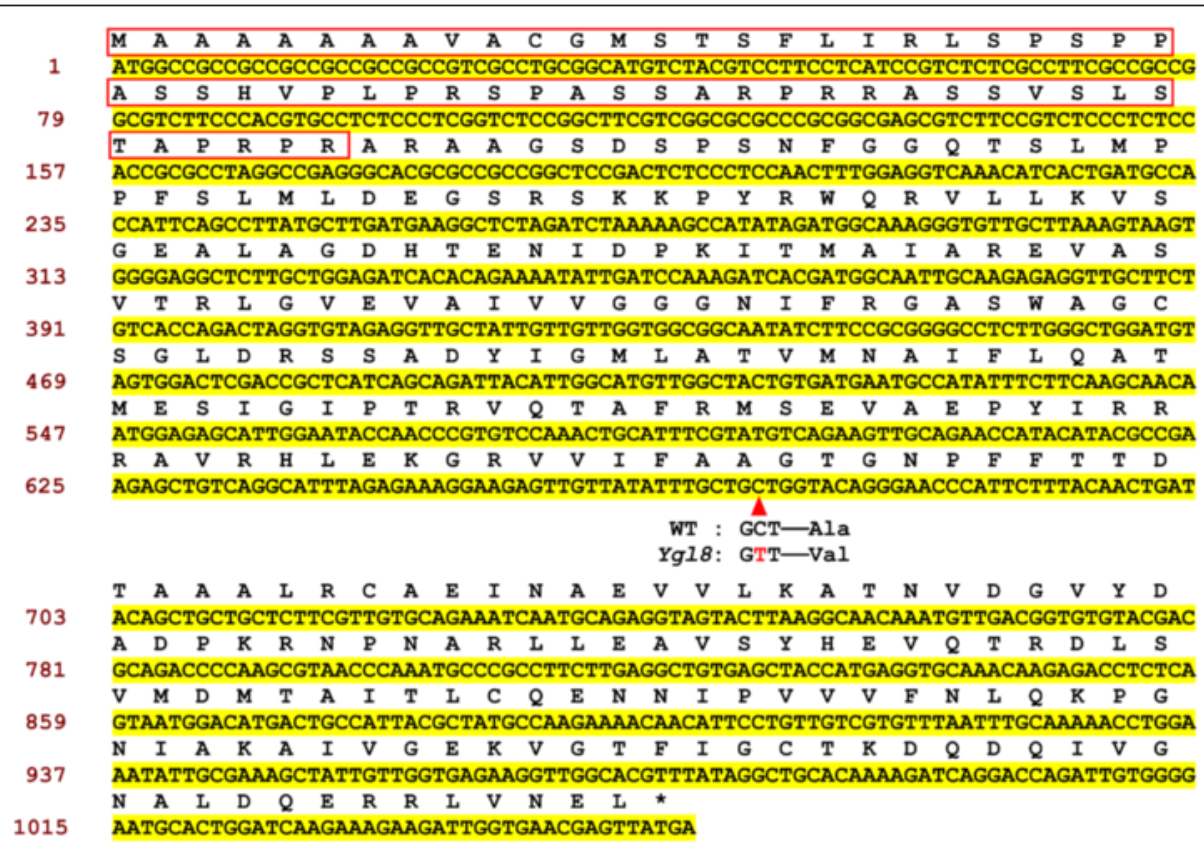

Fig. 5 The coding sequences and amino acids of the YGL8 protein. The red box indicates the predicted chloroplast signal peptide and the base marked with a red triangle shows the mutation site of $y g / 8$ 

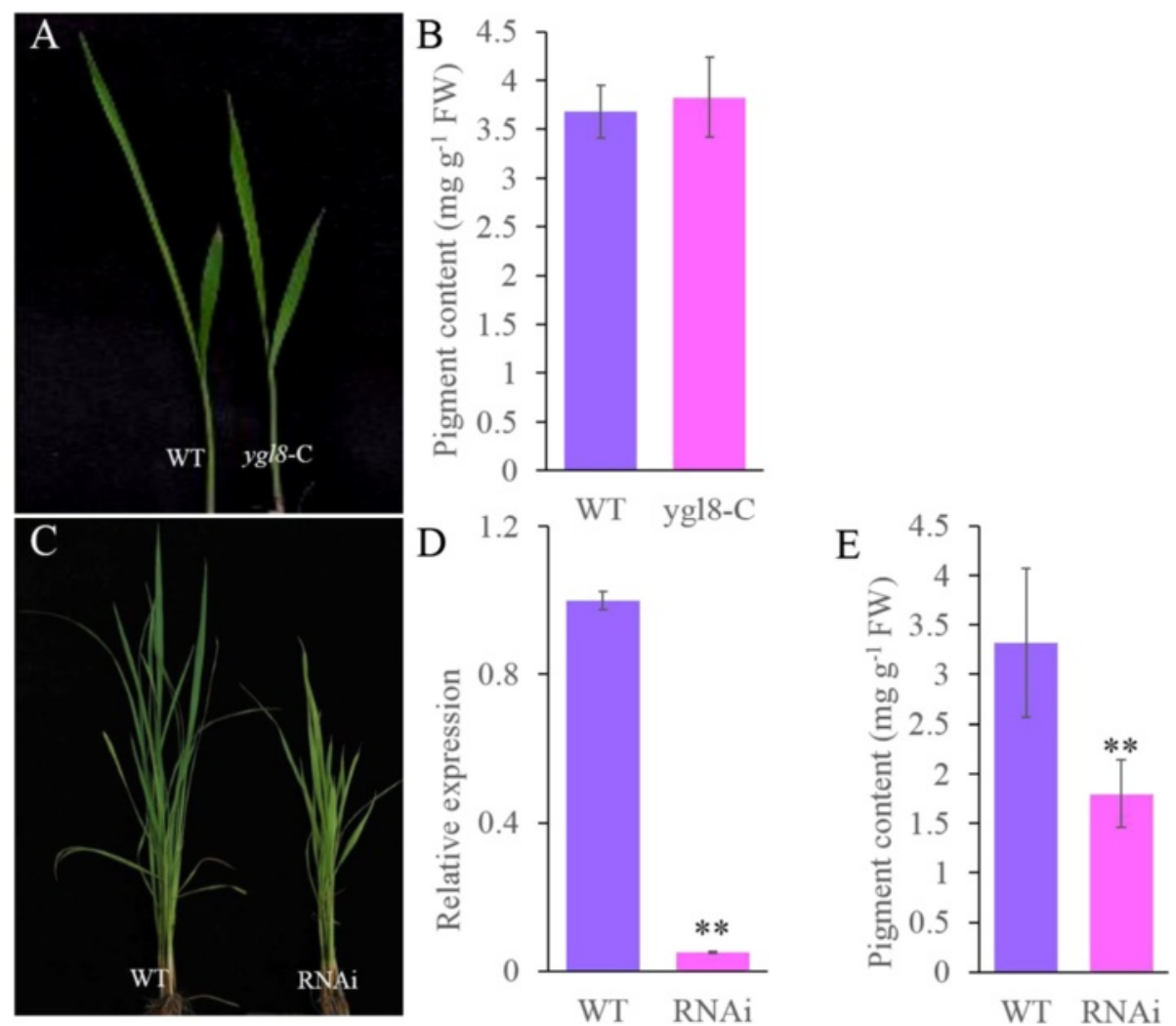

Fig. 6 Identification of YGL8. a: the phenotype of the WT and a complementation (yg/8-C) plant; $\mathbf{b}$ : the total level of Chl in WT and yg/8-C plants; c: the phenotype of the WT (ZhongHua11) and a RNAi plant; d: the expression levels of YGL8 in WT (ZhongHua11) and RNAi plants; e: the total level of Chl in WT (ZhongHua11) and RNAi plants; error bars represent standard deviation (SD) of three biological repeats; ** indicates significantly different compared with the corresponding WT at $p<0.01$ by the Student's $t$ test

acids at the $\mathrm{N}$-terminus. Thus, the mature protein had a predicted molecular weight of approximately $31.1 \mathrm{kDa}$. Subcellular location analysis in the rice protoplast indicated that the YGL8 protein functioned in chloroplasts (Fig. 7). Multiple sequence alignment and phylogenetic analysis indicated that YGL8 contained a conserved domain of a UMP kinase and shared significant similarity with other eukaryotic nuclear-encoded UMP kinases and their ancestral prokaryotic UMP kinases (Figs. 8 and 9). Most notably, in the conserved domain, YGL8 shared significant similarity with the conserved domain of cyanobacterial UMP kinases, including those of Chroococcales cyanobacterium CENA595, Anabaena sp. PCC 7108 and Nostoc punctiforme (Figs. 8 and 9).

\section{Expression patterns of YGL8}

qRT-PCR was applied to examine the expression pattern of YGL8 in WT and ygl8 mutant plants. At the booting stage, YGL8 was strongly expressed in leaf blades, while it was weakly expressed in the other tissues examined (Fig. 10a), the same results were obtained by semi-qPCR (Fig. 10b). Furthermore, there was no clear difference in YGL8 expression in leaf blades between the WT and the ygl8 mutant at the seedling, tillering and booting stages (Fig. 10c), which may indicate that the single amino acid mutation from Ala to Val in the YGL8 protein caused by the single base mutation from $\mathrm{C}$ to $\mathrm{T}$ in the YGL8 gene has no effect on the mRNA level.

\section{YGL8 affected the expression of genes related to} chloroplast development and the photosynthetic system We addressed the issue of whether the $y g l 8$ mutation affected the transcription of other genes associated with $\mathrm{Chl}$ biosynthesis and photosynthesis. The results of qRTPCR showed that the expression levels of genes involved in Chl biosynthesis, such as HEMC, HEME and PORA, were significantly reduced, at only $5.47,3.27$ and $14.86 \%$ of the levels in the WT, respectively, and the expression levels of CHLD, CHLM and CHLG were approximately half those in the WT. However, when compared with the wild type, the expression level of $C A O$ was slightly increased in the $y g l 8$ mutant (Fig. 11a). Interestingly, in the $y g l 8$ mutant, most of the expression levels of chloroplast genome encoded genes which we have examined were significant lower than those of the wild type to a different extent. Especially, three genes 


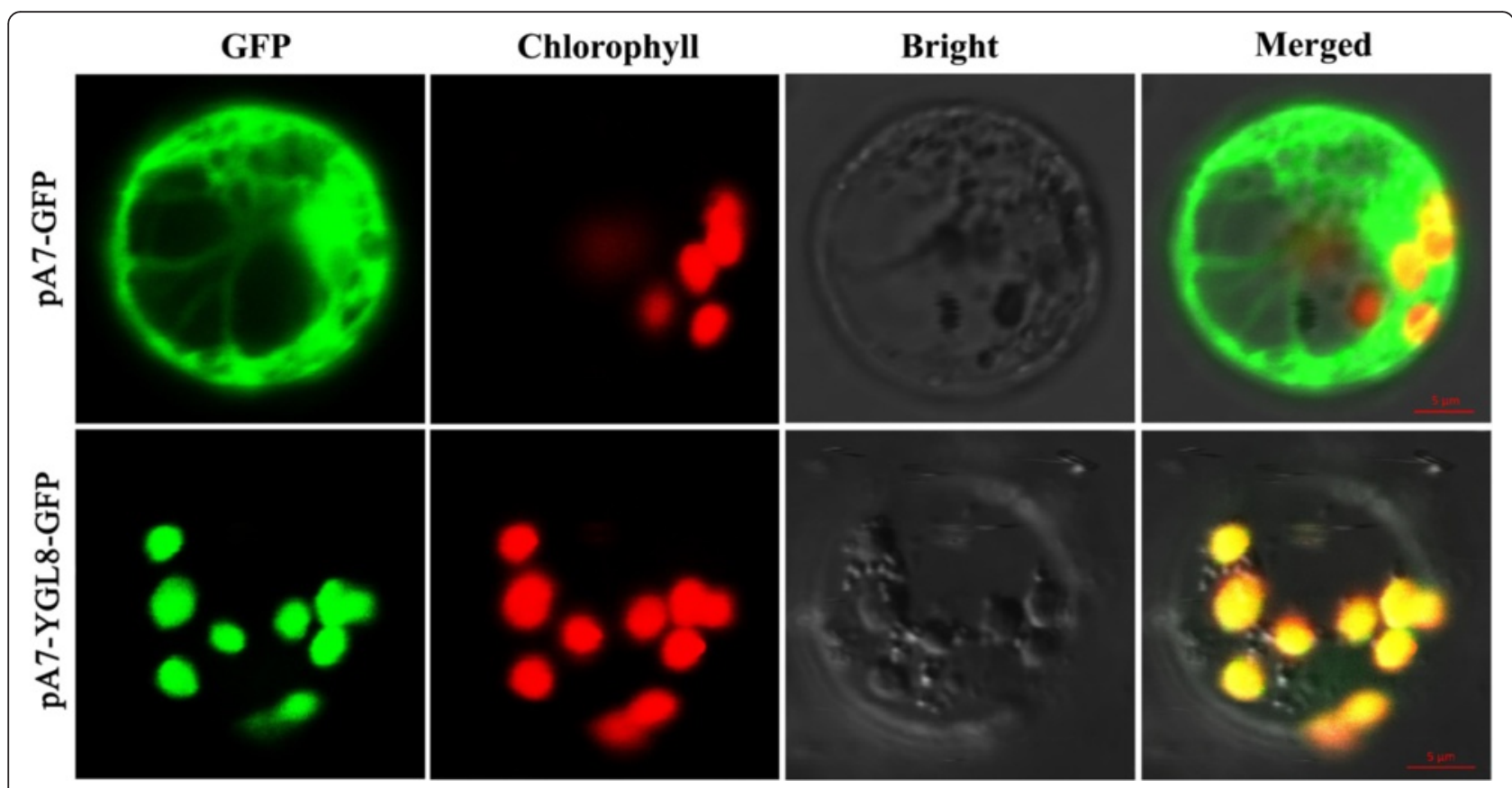

Fig. 7 Subcellular location of the YGL8 protein. YGL8 protein was targeted to the chloroplast

encoding photosystem reaction centre polypeptides, $p s a A$, $p s a B$, and $p s b C$ were reduced in $y g l 8$, at only $22.37,27.07$ and $30.9 \%$ of the expression levels in the WT, respectively. In addition, the expression levels of $p s b A, p s b B, p s b F$, $\operatorname{pet} B$, petD, $\operatorname{atp} A$, and $r b c L$ in the $y g l 8$ mutant were lower than those in the wild type, but the decreasing extent of corresponding gene was not high (Fig. 11b).

\section{Discussion}

Recently, substantial research has shown that leaf colour mutants are ideal for shedding light on the mechanisms of plant photosynthesis, the Chl biosynthesis pathway, the structure and function of chloroplasts, and crop agronomic traits [20]. In this study, using fine mapping, we identified a yellow-green leaf gene, YGL8, which is located near the telomere of the long arm of chromosome 1 (Fig. 4) and encodes a UMP kinase (Figs. 5 and 8). No other mutated genes located in that area of chromosome 1 was identified by map-based cloning and none of the other cloned genes encoded a UMP kinase. Therefore, YGL8 was identified as a novel gene that controls the development of leaf colour in rice.

YGL8 protein may have evolved from cyanobacterial UMP kinase and regulate the UMP/UMP/UTP level in chloroplasts

It is generally accepted that all chloroplasts are derived from a single cyanobacterial ancestor via the process of endosymbiosis [21]. During evolution, almost all cyanobacterial genes retained by eukaryotes relocated to the cell nucleus [22]. Therefore, the vast majority of chloroplast proteins are now imported as products of nuclear genes that encode chloroplast-targeted precursors synthesised on cytosolic ribosomes [23]. Since nuclear-encoded YGL8 is targeted to chloroplasts and shows high similarity to a homologous cyanobacterial protein, the YGL8 gene might also have moved from the chloroplast to the nuclear genome of rice over the course of evolution. This would be consistent with the results of Puthiyaveetil et al. [21], who showed that the gene for the chloroplast sensor kinase moved from chloroplasts to the nuclear genome in Arabidopsis during evolution. Research has shown that in plants, as the building blocks of DNA and RNA synthesis, all pyrimidines within the cell are derived from UMP, [17]. UMP kinase is a ubiquitous enzyme that catalyses the phosphorylation of UMP to UDP, with ATP as the preferred donor [24]. The roles of pyrimidine monophosphokinases in cell growth and proliferation have been widely studied. For example, in Escherichia coli, the product of the UMP kinase gene $(p y r H / s m b A)$ has been shown to influence cell proliferation. The $s m b A$ mutant showed decreased macromolecular synthesis, hypersensitive to SDS and a novel morphological phenotype under nonpermissive conditions [14]. In addition, in yeast, mutations in the UMP kinase gene have been shown to cause declines of $90 \%$ in UTP and CTP, which affects both RNA and protein synthesis and ultimately results in cell death [15]. In the model plant Arabidopsis thaliana, it 


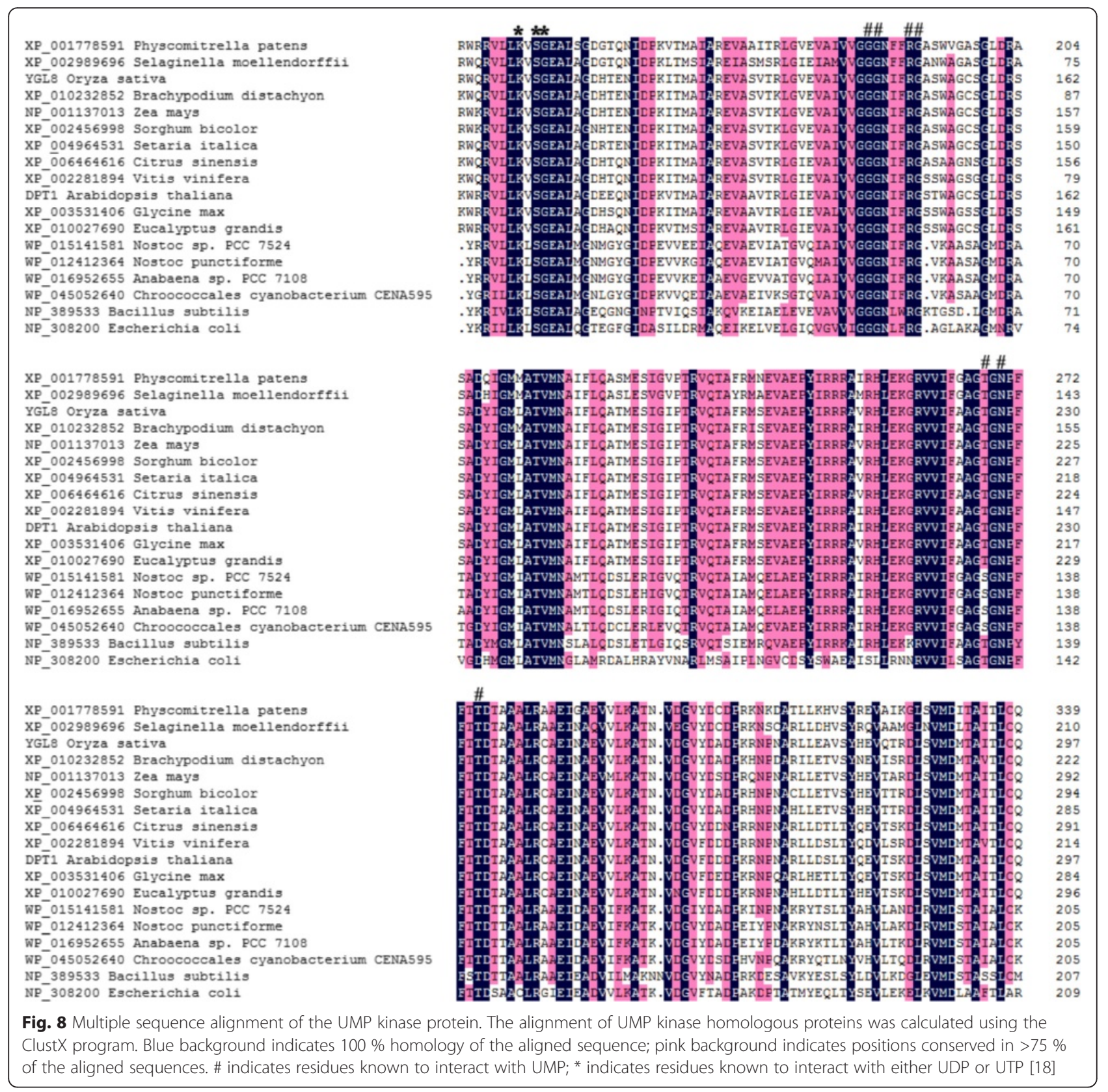

was reported that mutants of chloroplast-targeted UMP kinase (DPT1) failed to grow photo-autotrophically [18]. Here, we identified that the YGL8 gene encodes a chloroplast UMP kinase. The amino acid mutation from Ala to Val near the UMP binding site in the mutant protein (Figs. 4 and 5) might affect the enzyme activity of YGL8 and have a negative effect on the chloroplastic UTP pool, although this remains to be examined. These results indicate that nuclear-encoded and chloroplasttargeted YGL8, of cyanobacterial ancestry, may function in regulating the chloroplast UTP pool and influence chloroplast-encoded gene expression.
Mutation of YGL8 indirectly affects the expression of some nuclear-encoded chlorophyll biosynthesis-related genes

Chlorophyll plays a significant role in plant development and crop yield [27]. Chl metabolism has been extensively studied in various organisms by both biochemical [28] and genetic approaches [29]. Mutants with a deficiency in the ability to synthesize Chl, including CHLH, CHLD, CHLI and CHLG, exhibit growth defects and/or reduced yield to different extents $[5,6,11,30]$. In this study, we observed that the mutation of YGL8 affected the mRNA expression of some genes involved in $\mathrm{Chl}$ biogenesis: 


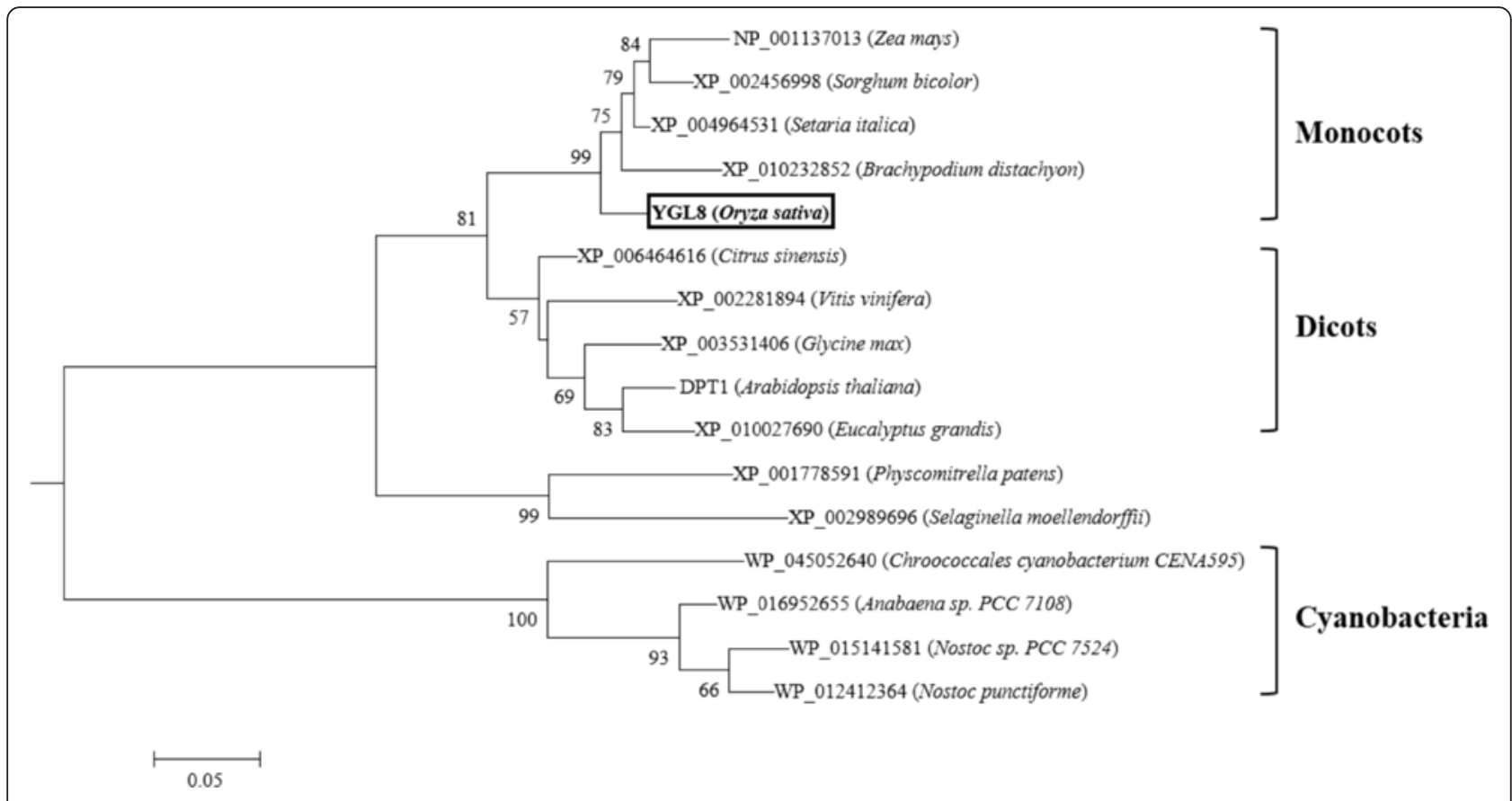

Fig. 9 Phylogenetic tree of prokaryotic and eukaryotic UMP kinases. The tree for UMP kinase homologue amino acid sequences was calculated and constructed using the MEGA program [19]

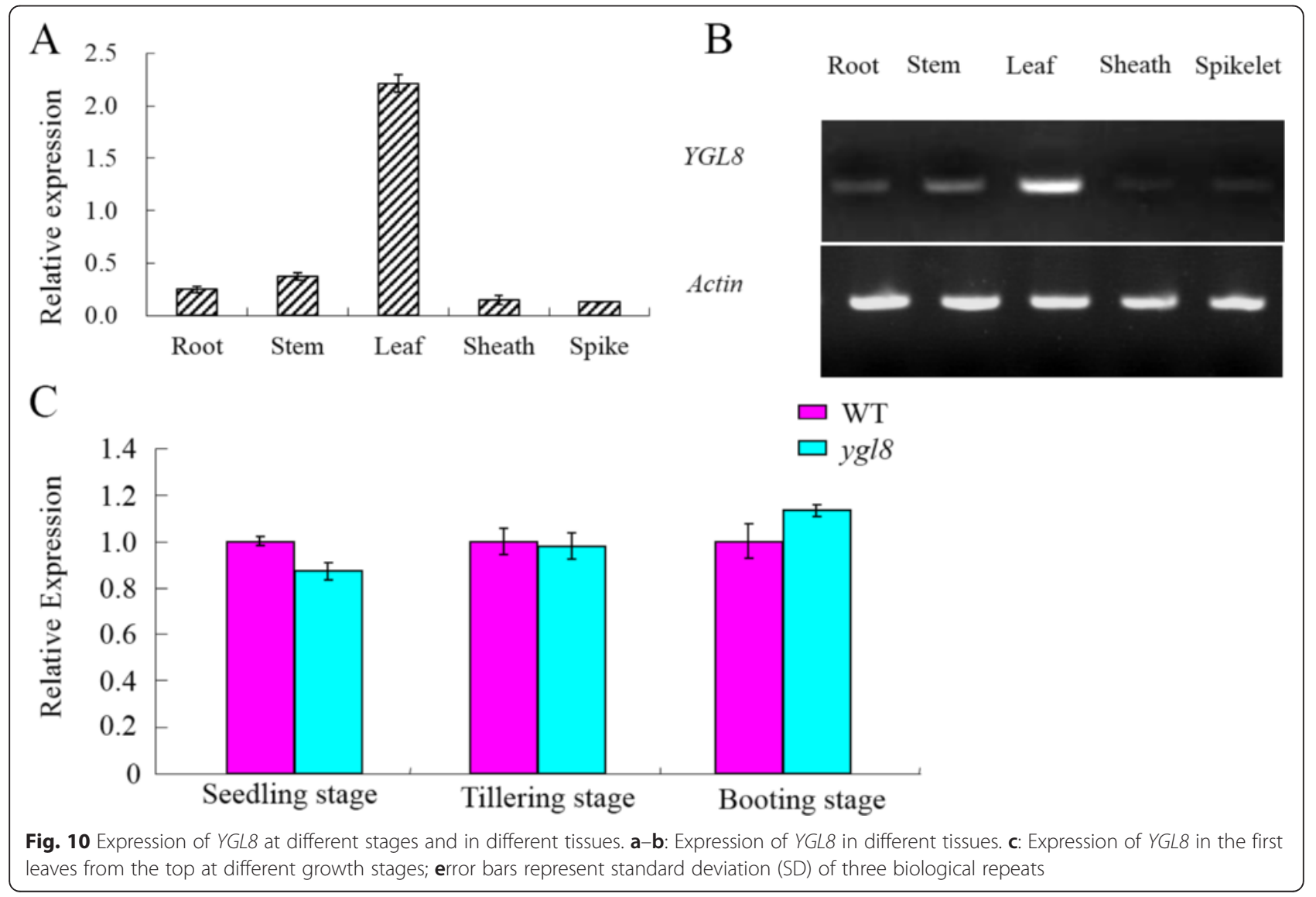




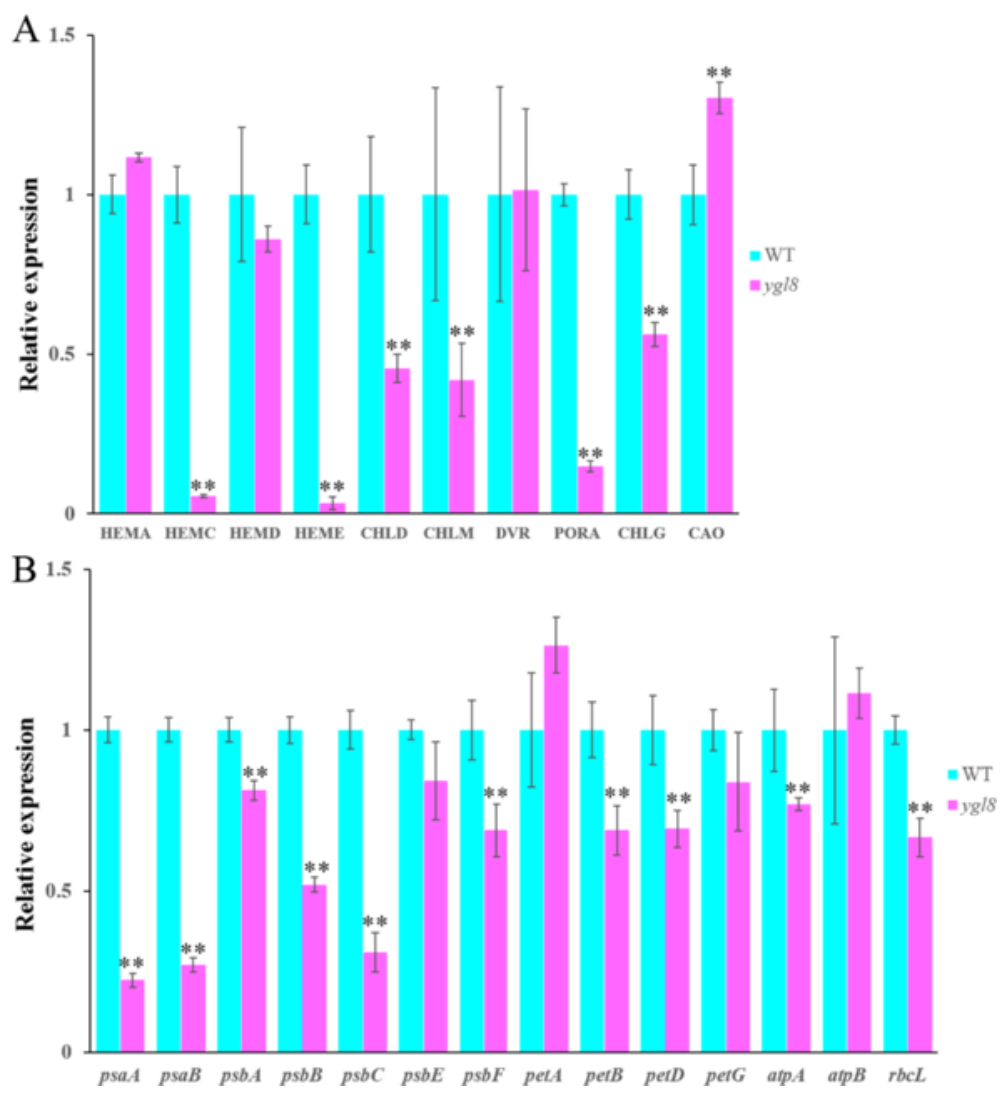

Fig. 11 The expression of different genes. a: The expression of Chl biosynthesis-related genes; $\mathbf{b}$ : the expression of chloroplast genome encoded genes; error bars represent standard deviation (SD) of three biological repeats; ${ }^{* *}$ indicates significantly different compared with the corresponding WT at $p<0.01$ by the Student's $t$ test

among the genes tested, the expression of $H E M C$, HEME, CHLD, CHLM, PORA and CHLG was reduced to different extents (Fig. 11a). This might be the main factor that led to the decreased $\mathrm{Chl} a$ level in the $y g l 8$ mutant (Table 1). One of the most important components of the light-harvesting pigment protein complexes of PS I and PS II, Chl $b$, is synthesised by $C A O$, which was reported to convert chlorophyllide $a$ (Chlide $a$ ) into Chlide $b$, most likely by two-step oxygenation [31]. Although the $y g l 8$ mutant retained a slightly increased mRNA level of CAO comparable to that of the WT (Fig. 11a), its Chl $b$ level was markedly lower (Table 1 ). The main reason for this reduced Chl $b$ content might be the significant blockage in $\mathrm{Chl} a$ biosynthesis. It has been reported that the ratio of $\mathrm{Chl} a / b$ is closely related to the mRNA levels of CAO in Arabidopsis [32]. However, the ratio of $\mathrm{Chl} a / b$ (Table 1 ) remained unchanged with a slightly increased CAO expression level. This might also be a consequence of decreased both Chl $a$ and $\mathrm{Chl} b$ levels in the $y g l 8$ mutant. These results suggest that YGL8 may function in influencing Chl $a$ and Chl $b$ biosynthesis.

\section{Mutation of YGL8 affects the expression of some chloroplast-encoded genes}

In eukaryotes, the two largest polypeptide subunits of PS I, PsaA and PsaB, both encoded by the plastome, form a heterodimer and bind to the primary electron donor of PS I, P700 [25]. It has been reported that mutants lacking the PsaA/B dimer generally failed to assemble the entire PS I core complex, although some peripheral subunits could still accumulate in the thylakoid membranes [26]. In the $y g l 8$ mutant, the level of $p s a A$ and $p s a B$ transcripts was found to be severely impaired (Fig. 11b), which implied that $y g l 8$ might also fail to assemble a functional PS I core complex, which would affect its photosynthesis. And this is consistent with the findings of Hein et al. [18], which showed that the dpt1-1 mutant of $A$. thaliana failed to grow photoautotrophically because of a reduced $p s a A$ and $p s a B$ mRNA level. Three genes of the chloroplast genome, $p s b A, p s b B, p s b C$ and $p s b F$, encoding $\mathrm{D} 1$ protein, $\mathrm{CP} 47$ protein, $\mathrm{CP} 43$ protein, and cytochrome b559 of the photosystem II reaction centre, respectively [39], exhibited different degrees of lower gene expression in the ygl8 mutant (Fig. 11b). 
Besides, other plastome-encoded genes, petB, petD, $\operatorname{atp} A$, and $r b c L$, encoding cytochrome b6, subunit IV of cytochrome $b / f$ complex, ATPase alpha subunit, and rubisco large subunit, respectively [39], showed lower expression level in the ygl8 mutant, in spite that the decreasing degree is not high (Fig. 11b). Thus, we suggest that the mutation of chloroplast-targeted UMP kinase in the $y g l 8$ mutant may affect the chloroplast UTP pool, which leads to the changing mRNA level of chloroplast genome encoded genes. Chloroplast thylakoid membranes are the main structure of energy transformation in plants. The four major functional membrane protein complexes of thylakoid membranes: the photosystem I and II, the cytochrome $b / f$ complex, and ATPase, act cooperatively to transfer light energy into available chemical energy [40]. Reduced expression level of thylakoid membrane genes in the ygl8 mutant which we have examined may lead to the abnormal structure (intumescent and hollow, Fig. 1f-g) and function (decreased photosynthetic rate, Fig. 3c; Additional file 2) of chloroplast thylakoid membranes. These results reveals that YGL8 may affect thylakoid membrane structure and function by influencing chloroplast genome encoded thylakoid membrane constitutive genes.

It is not yet fully understood why the mutation of chloroplast-targeted YGL8 affects nuclear-encoded Chl biosynthesis-related genes dramatically, and ultimately leads to a decline in the level of $\mathrm{Chl}$ in the ygl8 mutant. According to the recent reports and reviews on plastidto-nucleus retrograde signaling, it is clear that the expression of nuclear genes for plastid proteins is affected by the development and/or metabolic state of chloroplast $[41,42]$. Thus, one possible explanation might be that abnormal thylakoid membrane development resulted from the mutation of chloroplast-targeted UMP kinase by influencing the mRNA level of chloroplast genome encoded genes may inhibit Chl biosynthesisrelated gene expression by plastid-to-nucleus retrograde signaling.

\section{Conclusions}

In this study, a rice leaf yellowish mutant, $y g l 8$, was identified by screening of an EMS-induced mutant pool. By a map-based cloning method, the mutation of $y g l 8$ was shown to be located in a 54-kb genomic region between InDel marker ID-3 and SSR marker RM12339 on chromosome 1. Furthermore, a nucleotide mutation from $\mathrm{C}$ to $\mathrm{T}$ in Loc_Os01g73450 was identified. By transgenic complementation and RNAi methods, Loc_Os01g73450 was confirmed to be Ygl8. The nuclear-encoded chloroplasttargeted YGL8 protein contains a conserved UMP kinase domain and shares sequence similarity with UMP kinases of eukaryotic and prokaryotic (especially cyanobacterial) origins. The mutation of YGL8 had a negative impact on the expression of chloroplast genome-encoded thylakoid membrane constitutive genes, which affected the grana lamella structure and reduced the chlorophyll level, resulting in the yellowish phenotype, a reduced photosynthetic rate and poor yield characteristics. For further identification of the function and mechanism of action of the YGL8 protein, the following additional work is required: confirming the enzyme activity of YGL8; detecting and comparing the levels of UTP, UDP and UMP between the WT and the $y g l 8$ mutant; and testing the expression of other genes that may be regulated by YGL8.

\section{Methods}

\section{Plant materials}

The stably inherited mutation $y g l 8$ was derived from the progeny of an excellent indica restorer line Jinhui10 with seeds treated by $1 \%$ EMS. Jinhui10 plants represent the Wild-type. Xinong1A, a cytoplasmic male sterile line bred by the Rice Research Institute of Southwest University, Chongqing, China, was crossed with ygl8 and the $\mathrm{F}_{1}$ plants were self-crossed to generate the $F_{2}$ mapping population to genetic analysis and gene mapping of YGL8. Rice plants were cultivated under natural conditions in an experimental field at the Southwest University Rice Research Institute.

\section{Physiological analysis}

The first leaves from the top at the seedling stage, the tilling stage and heading stage of the WT and ygls were collected and used to measure the levels of photosynthetic pigments [33]. During the heading stage, at 9:00 am on a sunny day, the first leaves from the top of the WT and ygl8 were used to measure stomatal conductance, intercellular $\mathrm{CO}_{2}$ concentration, photosynthetic rate and transpiration rate with an LI-6400 portable photosynthesis meter (LiCor, Lincoln, NE, USA) in accordance with the manufacturer's instructions. Values are the means \pm SD of three biological repeats. The Student's $t$ test was applied for statistical analysis.

\section{Transmission electron microscopy}

The leaf cellular structure of WT and ygl8 plants was observed by TEM, as described by Wu et al. [6] with some modification. Leaves of WT and ygl8 was collected from 3-week-old plants grown in the experiment filed under natural conditions and fixed in primary fixative solution (3.5\% glutaraldehyde) and then post-fixed for $2 \mathrm{~h}$ with $1 \%$ osmium tetroxide after washing with $0.1 \mathrm{~mol} \mathrm{~L}^{-1}$ PBS buffer. Tissues were stained with uranyl acetate, dehydrated in ethanol and embedded in Spur's medium prior to thin sectioning. Samples were stained again and examined using an H-7500 TEM (Hitachi, Japan). 


\section{Survey of agronomic traits}

During the mature stage, $5 \mathrm{WT}$ and ygl8 mutant plants, respectively, were used to measure plant height, effective panicle number per plant, grain number per panicle, filled-grain number per panicle, seed-setting rate and 1000 -grain weight. Values are the means \pm SD of three biological repeats. The Student's $t$ test was applied for statistical analysis.

\section{DNA extraction, primer design and PCR protocol}

Bulked segregation analysis was employed for linkage analysis [34]. Total DNA of the parental lines or bulk DNA was extracted using the cetyl trimethyl ammonium bromide method [35], whereas genomic DNA of $\mathrm{F}_{2}$ individuals was isolated using an alkaline extraction method [36]. SSR markers were derived from http://archive.gramene.org/markers/microsat/ or identified by SSR Hunter. InDel primers were detected with Vector NTI software after genome re-sequenced between Xinong1A and Jinhui10. Newly developed markers used to map-cloning the YGL8 gene were listed in Table S1 in the Additional file 1. The total PCR reaction volume was $12.5 \mu \mathrm{L}$ and contained the following components: $1.25 \mu \mathrm{L}$ of $10 \times$ PCR buffer, $1 \mu \mathrm{L} 1 \mu \mathrm{mol} \mathrm{L} \mathrm{L}^{-1}$ primers, $1 \mu \mathrm{L}$ of $50 \mathrm{ng} \mu \mathrm{L}^{-1} \mathrm{DNA}, 0.75 \mu \mathrm{L}$ of $25 \mathrm{mmol} \mathrm{L}{ }^{-1} \mathrm{MgCl}_{2}, 0.5 \mu \mathrm{L}$ of $2.5 \mathrm{mmol} \mathrm{L}{ }^{-1} \mathrm{dNTPs}, 7.9 \mu \mathrm{L}$ of $\mathrm{ddH}_{2} \mathrm{O}$, and $0.1 \mu \mathrm{L}$ of 5 $\mathrm{U} \mu \mathrm{L}^{-1}$ Taq DNA polymerase. Amplifications were performed by the following procedure: $5 \mathrm{~min}$ at $94{ }^{\circ} \mathrm{C}$, followed by 35 cycles of $30 \mathrm{~s}$ at $94{ }^{\circ} \mathrm{C}, 30 \mathrm{~s}$ at $55^{\circ} \mathrm{C}$ and $1 \mathrm{~min}$ at $72{ }^{\circ} \mathrm{C}$, with a final extension at $72{ }^{\circ} \mathrm{C}$ for $10 \mathrm{~min}$. The PCR products were separated on $10 \%$ polyacrylamide gels and visualised by rapid silver staining [37].

\section{Genetic analysis and linkage map construction}

Recessive $F_{2}$ individuals showed banding patterns similar to those of Xinong1A (designated A), the ygl8 mutant (designated $\mathrm{B}$ ) and the $\mathrm{F}_{1}$ hybrid between Xinong1A and ygl8 (designated $\mathrm{H}$ ). Total $11212 \mathrm{~F}_{2}$ plants (8400 WT and 2812 recessive mutant plants) were used to genetic analysis and linkage map construction. The phenotypic ratios of segregating $F_{2}$ populations were evaluated using Pearson's Chi-square test for goodness-of-fit to the 3:1 (wild-type: mutant) ratio expected for single gene recessive mutation. Percentage genetic distances were calculated using the formula $[(H+2 A) / 2 n] \times 100$ and a linkage map was constructed accordingly. In this formula, $H$ is the number of $H$-type plants, $A$ is the number of A-type plants, and $n$ is the total number of $\mathrm{F}_{2}$ recessive individuals used for gene mapping of YGL8.

\section{Vector construction and rice transformation}

For complementation of the ygl8 mutation, a 6478-bp genomic fragment that contains 3844-bp Ygl8 genomic sequence including introns and extrons, coupled with 1570-bp upstream and 1054-bp downstream sequences, was amplified with YGL8com-F and YGL8com-R. The resulting PCR products was digested with $\mathrm{BamHI}$ and PstI, and cloned in to the binary vector Pcambia1301. The resulting recombinant plasmids were transformed into $y g l 8$ by $A$. tumefaciens-mediated transformation method as described previously [36]. To construct a RNAi vector for $Y G L 8$, a 334-bp fragment of YGL8 complementary DNA was amplified with the primers YGL8RNAi-F1 and YGL8RNAi-R1. The resulting PCR product was digested with $\mathrm{BamHI}$ and $\mathrm{KpnI}$ and inserted into vector pTCK303 [38] to obtain the intermediate vector. The PCR products amplified by YGL8RNAi-F2 and YGL8RNAi-R2 was digested with SacI and SpeI and cloned into the intermediate vector. The recombinant plasmids were transformed into Zhonghua11 plants by the $A$. tumefaciens-mediated transformation method. The primer sequences were listed in Table S2 (Additional file 3).

\section{Multiple sequence alignment and phylogenetic tree construction}

Protein sequences applied in multiple sequence alignment and phylogenetic tree construction were acquired by searching Phytozome (http://phytozome.jgi.doe.gov/ pz/portal.html) using the YGL8 sequence as a query. Multiple sequence alignment was performed with ClustalX software using multiple alignment modes. Phylogenetic tree was constructed by MEGA 5.2 with the maximum likelihood method with JTT model. The bootstrap support values for each node were from 500 replications and shown next to the branches [19].

\section{Subcellular location}

The full-length coding sequence of YGL8 was amplified with YGL8SL-F and YGL8SL-R, the resulting PCR products were digested with the XhoI and SpeI and cloned into vector pA7-GFP. Both pA7-YGL8-GFP and empty pA7-GFP vector were transformed into rice protoplasts [19]. GFP fluorescence was detected using a confocal laser scanning microscope (Olympus FluoView FV1000; Japan). YGL8SL-F and YGL8SL-R were listed in Table S2 (Additional file 3).

\section{Quantitative real-time PCR}

Total rice RNA was extracted from the roots, culms, leaf sheaths, flag leaves, young panicles (white) and green panicles at the heading stage using an RNAprep Pure Plant kits (Tiangen Co. Ltd., China). First-strand cDNAs were synthesized using a PrimeScript RT Reagent Kit with gDNA Eraser (Perfect Real Time) (Takara Bio Inc., China). qRT-PCR was performed using the SYBR Premix Ex Taq II (Tli RNaseH Plus) kit (Takara Bio Inc., China) in an ABI Prism 7500 Real-Time PCR System 
(Invitrogen, USA). Relative expression levels of genes were calculated using the formula $2^{-\Delta \Delta \mathrm{Ct}}$ and are expressed relative to OsActin1. Values are the means $\pm \mathrm{SD}$ of three biological repeats. The Student's $t$ test was applied for statistical analysis. The qRT-PCR primers used in this study was listed in Table S3 in the Additional file 3.

\section{Additional files}

Additional file 1: Statistics of agronomic traits of the wild-type and yg/8 mutant. (PPTX $36 \mathrm{~kb}$ )

Additional file 2: Statistics of photosynthetic parameters of yg/8 mutant in comparison to the wild-type. (PPTX $36 \mathrm{~kb}$ )

Additional file 3: Primer sequences used in this study. (DOC $61 \mathrm{~kb}$ )

\section{Abbreviations}

$\mathrm{CAO}$, chlorophyllide a oxygenase; CDS, coding sequence; $\mathrm{Chl} a$, chlorophyll $a$; Chl b, chlorophyll b; Chl, chlorophyll; CHLD, Mg chelatase D subunit; CHLG, chlorophyll synthase; CHLM, Mg protoporphyrin methyltransferase; DVR, 3,8-Divinyl reductase protochlorophyll a-8-vinyl reductase; EMS, ethyl methane sulfonate; HEMA, glutamyl-tRNA reductase; HEMC, hydroxymethylbilane synthase; HEMD, uroporphyrinogen III synthase; HEME, uroporphyrinogen decarboxylase; InDel markers, insertion/deletion markers; JTT model, Jones-Taylor-Thornton model; NADPH, pchlide oxidoreductase; ORFs, open reading frames; PORA; PsaA, photosystem I P700 chlorophyll a apoprotein A1; PsaB, photosystem I P700 chlorophyll a apoprotein A2; QRT-PCR, quantitative real time-polymerase chain reaction; rbcL, rubisco large subunit; RNAi, RNA interference; SSR, simple sequence repeat; TEM, transmission electron microscopy; UDP, uridine diphosphate; UMP, uridine monophosphate; UMP kinase; UTP, uridine triphosphate

\section{Acknowledgements \\ Authors are thank to Dr. Yunfeng Li, Key Laboratory of Application and Safety Control of Genetically Modified Crops, Rice Research Institute of Southwest University, Chongqing 400716, China, for providing technical support.}

\section{Funding}

This study was funded in part by the Natural Science Foundation of China (31171178), the Ministry of Agriculture's Public Welfare Industry Scientifci Research Special Project (201303129), the Ability Improvment Project of Chongqing (cstc2014pt-sy80001), and the Application Development Key Project of Chongqing (cstc2014yykfB80009).

\section{Availability of data and materials}

All the data and materials supporting our research findings are contained in the methods section of the manuscript. Also, details are provided in the supplementary data attached with the manuscript.

\section{Authors' contributions}

$H G$ and $S X$ designed the experiments and together with, GS and DQ carried out genetic analysis, linkage mapping and molecular cloning, ZX, WZ and XY carried out physiological analysis, functional analysis and gene expression assays. ZT, SW, and LY carried rice transgenic experiments. All authors read and approved the final manuscript.

\section{Competing interests}

The authors declare that they have no competing interests.

\section{Consent for publication}

Not applicable.

Ethics approval and consent to participate Not applicable.

\section{Author details}

'Key Laboratory of Application and Safety Control of Genetically Modified Crops, Rice Research Institute of Southwest University, Chongqing 400716, China. ${ }^{2}$ Institute of Rice, Chongqing Academy of Agricultural Sciences, Chongqing 401329, China. ${ }^{3}$ Forestry Bureau of Chuanshan District, Suining, Sichuan 629000, China.

Received: 13 December 2015 Accepted: 25 May 2016

Published online: 13 June 2016

\section{References}

1. Gustafsson A. The plastid development in various types of chlorophyll mutations. Hereditas. 1942;28(3-4):483-92.

2. Awan MA, Konzak CF, Rutger JN, Nilan RA. Mutagenic effects of sodium azide in rice. Crop Sci. 1980;20(5):663-8

3. Falbel TG, Staehelin LA. Partial blocks in the early steps of the chlorophyll synthesis pathway: a common feature of chlorophyll b-deficient mutants. Physiol Plant. 1996:97(2):311-20.

4. Miyoshi K, Ito Y, Serizawa A, Kurata N. OsHAP3 genes regulate chloroplast biogenesis in rice. Plant J. 2003;36(4):532-40.

5. Lee $\mathrm{S}$, Kim JH, Yoo ES, Lee $\mathrm{CH}$, Hirochika H, An G. Differential regulation of chlorophyll a oxygenase genes in rice. Plant Mol Biol. 2005;57(6):805-18.

6. Wu ZM, Zhang X, He B, Diao LP, Sheng SL, Wang JL, Guo XP, Su N, Wang $L F$, Jiang L, Wang CM, Zhai HQ, Wan JM. A chlorophyll-deficient rice mutant with impaired chlorophyllide esterification in chlorophyll biosynthesis. Plant Physiol. 2007;145(1):29-40.

7. Dong $H$, Fei GL, Wu CY, Wu FQ, Sun $Y Y$, Chen $M J$, Ren $Y L$, Zhou $K N$, Cheng ZJ, Wang JL, Jiang L, Zhang X, Guo XP, Lei CL, Su N, Wang HY, Wan JM. A rice virescent-yellow leaf mutant reveals new insights into the role and assembly of plastid caseinolytic protease in higher plants. Plant Physiol. 2013;162(4):1867-80.

8. Sugimoto H, Kusumi K, Noguchi K, Yano M, Yoshimura A, Iba K. The rice nuclear gene, VIRESCENT 2, is essential for chloroplast development and encodes a novel type of guanylate kinase targeted to plastids and mitochondria. Plant J. 2007:52(3):512-27.

9. Chen H, Cheng ZJ, Ma XD, Wu H, Liu YL, Zhou KN, Chen YL, Ma WW, Bi JC, Zhang X, Guo XP, Wang JL, Lei CL, Wu FQ, Lin QB, Liu YQ, Liu LL, Jiang L. A knockdown mutation of YELLOW-GREEN LEAF2 blocks chlorophyll biosynthesis in rice. Plant Cell Rep. 2013;32(12):1855-67.

10. Yoo SC, Cho SH, Sugimoto H, Li J, Kusumi K, Koh HJ, Iba K, Paek NC. Rice Virescent3 and Stripel encoding the large and small subunits of ribonucleotide reductase are required for chloroplast biogenesis during early leaf development. Plant Physiol. 2009;150(1):388-401.

11. Zhang HT, Li JJ, Yoo JH, Yoo SC, Cho SH, Koh HJ, Seo HS, Paek NC. Rice Chlorina-1 and Chlorina-9 encode ChID and Chll subunits of Mg-chelatase, a key enzyme for chlorophyll synthesis and chloroplast development. Plant Mol Biol. 2006:62(3):325-37.

12. Shi J, Wang Y, Guo S, Ma L, Wang Z, Zhu X, Sang X, Ling Y, Wang N, Zhao $F$, He G. Molecular mapping and candidate gene analysis of a Yellow-Green Leaf 6 (ygl6) mutant in rice. Crop Sci. 2015;55(2):669-80.

13. Deng XJ, Zhang HQ, Wang Y, He F, Liu JL, Xiao X, Shu ZF, Li W, Wang GH, Wang GL. Mapped clone and functional analysis of leaf-color gene Ygl7 in a rice hybrid (Oryza sativa L. ssp. indica). PLoS ONE. 2014;9(6):e99564.

14. Yamanaka K, Ogura T, Niki H, Hiraga S. Identification and characterization of the smbA gene, a suppressor of the mukB null mutant of Escherichia coli. J Bacteriol. 1992;174(23):7517-26.

15. Liljelund P, Lacroute F. Genetic characterization and isolation of the Saccharomyces cerevisiae gene coding for uridine monophosphokinase. Mol Gen Genet. 1986;205(1):74-81.

16. Giblett ER, Anderson JE, Chen S-H, Teng Y-S, Cohen F. Uridine monophosphate kinase: a new genetic polymorphism with possible clinical implications. Am J Hum Genet. 1974;26:627-35.

17. Zhou L, Lacroute F, Thornburg R. Cloning, expression in Escherichia coli, and characterization of Arabidopsis thaliana UMP/CMP kinase. Plant Physiol. 1998;117(1):245-54.

18. Hein P, Stockel J, Bennewitz S, Oelmüller R. A protein related to prokaryotic UMP kinases is involved in psaA/B transcript accumulation in Arabidopsis. Plant Mol Biol. 2009;69(5):517-28.

19. Ren DY, Li YF, Zhao FM, Sang XC, Shi JQ, Wang N, Guo S, Ling YH, Zhang CW, Yang ZL, He GH. MULTI-FLORET SPIKELET1, which encodes an AP2/ERF protein, determines spikelet meristem fate and sterile lemma identity in rice. Plant Physiol. 2013;162(2):872-84 
20. Larkin RM, Alonso JM, Ecker JR, Chory J. GUN4, a regulator of chlorophyll synthesis and intracellular signaling. Science. 2003;299(5608):902-6.

21. Puthiyaveetil S, Kavanagh TA, Cain P, Sullivan JA, Newell CA, Gray JC, Robinson C, Giezen MVD, Rogers MB, Allen JF. The ancestral symbiont sensor kinase CSK links photosynthesis with gene expression in chloroplasts. Proc Natl Acad Sci. 2008;105(29):10061-6.

22. Martin W, Rujan T, Richly E, Hansen A, Cornelsen S, Lins T, Leister D, Stoebe B, Hasegawa M, Penny D. Evolutionary analysis of Arabidopsis, cyanobacterial, and chloroplast genomes reveals plastid phylogeny and thousands of cyanobacterial genes in the nucleus. Proc Natl Acad Sci U S A. 2002:99(19):2246-12251.

23. Ellis RJ. Nuclear domination of chloroplast development. Sci Prog. 1984; 69(273):129-42.

24. Labesse G, Bucurenci N, Douguet D, Sakamoto H, Landais S, Gagyi C, et al. Comparative modelling and immunochemical reactivity of Escherichia coli UMP kinase. Biochem Biophys Res Commun. 2002;294(1):173-9.

25. Chitnis PR. Photosystem I: function and physiology. Annu Rev Plant Biol. 2001;52(1):593-626.

26. Redding K, Cournac L, Vassiliev IR, Golbeck JH, Peltier G, Rochaix JD. Photosystem I is indispensable for photoautotrophic growth, $\mathrm{CO}_{2}$ fixation, and $\mathrm{H}_{2}$ photoproduction in Chl amydomonas reinhardtii. J Biol Chem.1999; 274(15):10466-73.

27. Fromme P, Melkozernov A, Jordan P, Krauss N. Structure and function of photosystem I: interaction with its soluble electron carriers and external antenna systems. FEBS Lett. 2003;555(1):40-4.

28. Pontoppidan B, Kannangara CG. Purification and partial characterisation of barley glutamyl-tRNAGlu reductase, the enzyme that directs glutamate to chlorophyll biosynthesis. Eur J Biochem. 1994;225(2):529-37.

29. Tanaka A, Ito H, Tanaka R, Tanaka NK, Yoshida K, Okada K. Chlorophyll a oxygenase (CAO) is involved in chlorophyll b formation from chlorophyll a. Proc Natl Acad Sci U S A. 1998;95(21):12719-23.

30. Jung KH, Hur J, Ryu CH, Choi Y, Chung YY, Miyao A, et al. Characterization of a rice chlorophyll-deficient mutant using the T-DNA gene-trap system. Plant Cell Physiol. 2003;44(5):463-72.

31. Oster U, Tanaka R, Tanaka A, Rudiger W. Cloning and functional expression of the gene encoding the key enzyme for chlorophyll b biosynthesis (CAO) from Arabidopsis thaliana. Plant J. 2000:21 (3):305-10

32. Harper AL, Gesjen SE, Linford AS, Peterson MP, Faircloth RS, Thissen MM, et al. Chlorophyllide a oxygenase mRNA and protein levels correlate with the chlorophyll a/b ratio in Arabidopsis thaliana. Photosynth Res. 2004;79(2):149-59.

33. Wellburn AR. The spectral determination of chlorophylls $a$ and $b$, as well as total carotenoids, using various solvents with spectrophotometers of different resolution. Plant Physiol. 1994;144(3):307-13.

34. Michelmore RW, Paran I, Kesseli RV. Identification of markers linked to disease-resistance genes by bulked segregant analysis: a rapid method to detect markers in specific genomic regions by using segregating populations. Proc Natl Acad Sci. 1991;88(21):9828-32.

35. Murray MG, Thompson WF. Rapid isolation of high molecular weight plant DNA. Nucleic Acids Res. 1980;8(19):4321-6.

36. Sang XC, Li YF, Luo ZK, Ren DY, Fang LK, Wang N, et al. CHIMERIC FLORAL ORGANS1, encoding a monocot-specific MADS box protein, regulates floral organ identity in rice. Plant Physiol. 2012;160(2):788-807.

37. Ren DY, Rao YC, Huang LC, Leng YJ, Hu J, Lu M, et al. Fine mapping identifies a new QTL for brown rice rate in rice (Oryza Sativa L.). Rice. 2016;9:4.

38. Wang $M$, Chen $C$, Xu YY, Jiang RX, Han $Y, X u Z H$, et al. A practical vector for efficient knockdown of gene expression in rice (Oryza sativa L.). Plant Mol Biol Rep. 2004;22(4):409-17.

39. Hiratsuka J, Shimada H, Whittier R, Ishibashi T, Sakamoto M, Mori M, et al. The complete sequence of the rice (Oryza sativa) chloroplast genome: Intermolecular recombination between distinct tRNA genes accounts for a major plastid DNA inversion during the evolution of the cereals. Mol Gen Genet. 1989;217(2-3):185-94.

40. Andersson B, Barber J. Composition, organization, and dynamics of thylakoid membranes. Adv Mol Cell Biol. 1994;10:1-53.

41. Nott A, Jung HS, Koussevitzky S, Chory J. Plastid-to-nucleus retrograde signaling. Annu Rev Plant Biol. 2006;57:739-59.

42. Singh R, Singh S, Parihar P, Singhb VP, Prasada SM. Retrograde signaling between plastid and nucleus: a review. J Plant Physiol. 2015;181:55-66.

\section{Submit your next manuscript to BioMed Central and we will help you at every step:}

- We accept pre-submission inquiries

- Our selector tool helps you to find the most relevant journal

- We provide round the clock customer support

- Convenient online submission

- Thorough peer review

- Inclusion in PubMed and all major indexing services

- Maximum visibility for your research

Submit your manuscript at www.biomedcentral.com/submit
Biomed Central 